\title{
Socioeconomic level and the parents' perception of the impact of oral diseases on their children's quality of life
}

\author{
Naiana de Melo Belila1', Ronald Jefferson Martins', Cléa Adas Saliba Garbin'1 , Wanilda Maria Meire Costa Borghi ${ }^{2}$ \\ ${ }^{1}$ Universidade Estadual Paulista - UNESP, School of Dentistry of Araçatuba, Department of Children and Social Dentistry, Araçatuba, SP, Brazil
}

Received for publication: November 08, 2016 Accepted: March 08, 2017

Correspondence to: Ronald Jefferson Martins NEPESCO - Center for Research in Public Health Faculdade de Odontologia de Araçatuba - UNESP Departmento de Odontologia Infantil e Social Rua José Bonifácio, nº 1193 - Vila Mendonça CEP. 16015-050 - Araçatuba-SP - Brasil Phone: +55 18 3636-2824 E-mail: rojema@foa.unesp.br

\begin{abstract}
Aim: To analyze how parents of different socioeconomic levels perceive the impact of oral diseases on their children's quality of life. Methods: All parents or guardians of students aged 11 to 14 years old, regularly enrolled in fundamental schooling at public schools of two towns in the northwestern region of the State of São Paulo, Brazil, were enrolled in the study. The questionnaire of "Socioeconomic Assessment Tool" was used to classify the families with regards to socioeconomic class and the "Parental-Caregiver Perceptions Questionnaire (P-CPQ)" was used to verify the parents' perception of the impact of oral diseases on their children's quality of life. Results: $172(41.8 \%)$ individuals answered the survey. Among them, most belonged to the Upper Low Class (61\%). $21.5 \%$ of the individuals answered that they considered their children's oral health "regular or bad" and $71.5 \%$ answered that their child's general well-being was not or was little affected by the condition of his/ her teeth, lips, jaws or mouth. There was an association between the quality of life sub-scales, especially "oral symptoms", with all socioeconomic classes. Conclusions: There is a relationship between parents' socioeconomic class and the perception of the impact of oral disease on their children's quality of life.
\end{abstract}

Keywords: Social Class. Oral Health. Quality of Life.

\section{Introduction}

Good oral health condition is critical to maintaining the general welfare of the individual, allowing him or her to perform their daily functions normally with a healthy quality of life ${ }^{1}$.

The effects of tooth decay and other oral diseases reflect many negative aspects in the lives of people who are still in the infancy stage and adolescence, such as difficulties to socialize, chew, swallow, speak, sleep, lack of appetite, low self-esteem and behavior changes; that can harm even school performance ${ }^{2}$.

Parents' knowledge and perception about oral health originates from their culture, beliefs, habits and environment. This in turn, influences directly their children's behavior and oral conditions ${ }^{3}$. Hygiene habits and healthy eating habits tend to be a family characteristic. Thus the influence of parents on their children's oral health, from childhood to adolescence, is unequivocal ${ }^{4}$.

The income and low levels of education are closely related to poor hygiene and nutrition of the families, as well as unpleasant experiences of early childhood caries, both by the parents and the children, which consequently influences the quality of life of individuals $\mathrm{s}^{3,5}$. 
The quality of life is defined, according to the World Health Organization as "the individual's perception of their position in life in the context of culture and value system in which they live, and in relation to their goals, expectations, standards and concerns"6. This concept is multidimensional and includes both positive and negative factors in relation to the overall well-being due to social, economic and cultural aspects of the individual ${ }^{2}$.

For a long time, oral health had been measured only through clinical examinations, which does not allow for the evaluation of the impact that oral diseases cause on individuals, requiring new tools for a more accurate analysis ${ }^{2}$.

In this context, this study aimed to analyze how parents of different socioeconomic levels perceived the impact of oral diseases on the quality of life of their children, who were public school students of two small towns in the northwestern region of the State of São Paulo, in Brazil.

\section{Material and methods}

The study consisted of a descriptive transversal survey, with a quali-quantitative approach. It was carried out from July to September 2015, in fundamental schools in two towns in the northwestern region of the State of São Paulo, Brazil: Américo de Campos and Pontes Gestal. These cities were chosen because they have small, predominantly urban population and a similar Human Development Index (HDI), income (HDI income) and education (HDI Education).

All parents or guardians of students aged 11 to 14 years old regularly enrolled in fundamental schooling of public schools of the towns participated. Those who did not answer the questionnaire completely and those who did not sign the informed consent form were excluded.

The sample size should be 134 individuals, when calculated with sampling error of $7 \%$ and confidence level of $93 \%$, so the sample obtained was $22.1 \%$ greater than the sample size.

Initially, the municipal secretaries of education and the principals of the schools were informed about the aim of the survey and the future use of the data collected, in order to obtain their support for the study. The same information was passed on to the students' parents at the parent-teacher conference.

Later, two questionnaires were handed to the parents:

a) Socioeconomic Assessment Tool, to classify the families with regards to socioeconomic class. In the scale in this tool, the family's economic status scores from 1 to 21 points (from gross income up to $1 / 2$ minimum wage to over 100 minimum wages), the number of family members living in the household from 1 to 6 points (from over 8 to 1 to 2 members), the education level of the members from 0 to 7 points (from illiterate to graduate diploma), the housing condition / situation from 0 to 10 points, and the occupation of the head of household from 1 to 13 points. The sum of these indicators classifies the families in six classes, Lower Lower class (LL), Upper Lower class (UL), Lower Middle class (LM), Middle class (MI), Upper Middle class (UM) and Upper class (UP), classification in which the "Upper Class" (from 55 to 57 points) is the is the most affluent and the "Lower Lower Class" (from 0 to 20 points) the least affluent ${ }^{7}$. b) Parental-Caregiver Perceptions Questionnaire (P-CPQ). A questionnaire consisting of 35 questions to assess parents or guardians' perception of the impact of oral diseases (cavities, malocclusion, etc, for instance) on the quality of life of their children. Questions 1 and 2 refer to the global perception of caregivers about oral health and general well-being of the child. The possible answers to question 1 range from "excellent" to "bad" and to question 2 range from "not at all" to "very much". The other questions are subdivided into four broad categories: oral symptoms (questions 3 to 8), functional limitations (questions 9 to 16 ), emotional well-being (questions 17 to 24 ), and social well-being (questions 25 to 35). The answer options are presented in a Likert-type scale, which ranges from zero to four points $(0$ $=$ never; 1 = once or twice; 2 = sometimes; 3 = frequently; 4 = every day or nearly every day). The answer option "I don't know" was marked as "0" (zero), based on the studies of Jokovic et al. ${ }^{8}$, as the data indicate that the children "Never" reported that item to their parents. The total score is obtained by the sum of the scores of all questions. The greater the score, the greater the impact of oral diseases on the quality of life ${ }^{9}$. P-CPQ was originally developed in English, in Toronto, Canada, by Jokovic et al..$^{8,10}$ and transculturally adapted in Brazilian Portuguese and validated by Barbosa et al. ${ }^{2}$. It has shown to be valid and reliable to assess parents' perception'.

Regarding P-CPQ, a descriptive analysis of the results of the first question, about socioeconomic classes and how parents or guardians considered their children's oral health, and the second, about socioeconomic classes and how much the parents thought that their child's general well-being was affected by his/her oral health, was made because they cannot be included in the sum of the subscale scores.

The scales of this questionnaire were analyzed by BioStat 5.0 software $^{11}$. As the score was not evenly distributed, Kruskal Wallis non parametric test with significance level of $5 \%$ was used to assess the difference of mean scores among the groups of the different socioeconomic classes. As a significant difference was detected among the socioeconomic classes, Dunn's Test of multiple comparisons was performed.

The study was approved by the Research in Humans Ethics Committee, within the standards required by Resolution 466/12, CAAE process no. 39094214.2.0000.5420. All participants signed an Informed Consent Form.

\section{Results}

The universe of the research comprised 412 parents or guardians, from which 172 (41.8\%) answered the survey.

Based on the Socioeconomic Assessment Tool, 20.4\% of the heads of household belonged to LL Class, $61 \%$ to UL Class, $14.5 \%$ to LM Class and $4.1 \%$ to MI Class. As only one participant belonged to UM Class, that one was included in the MI Class.

Concerning P-CPQ, the reliability of internal consistency of subscales among the participants' responses was estimated by the Cronbach alpha coefficient $(n=0,887)$. The first question was how the caregiver would classify his/her child's health with regards to teeth, lips, jaws and mouth, and $21.5 \%$ of the individuals 
answered that considered it "regular or bad". The second question was how much his/her child's general well being was affected by the condition of his/her teeth, lips, jaws or mouth, and $71.5 \%$ answered "not at all" or "just a little" (Tables 1 and 2).

Table 1 - Number and percentage of parents or guardians with regards to the perception of their children's oral health and socioeconomic classes, Américo de Campos/Pontes Gestal, Brazil, 2015.

\begin{tabular}{lccccccccccccc}
\hline \multicolumn{10}{c}{ How would you classify the health of child's teeth, lips, jaws and mouth? } \\
\hline & \multicolumn{1}{c}{ Excellent } & \multicolumn{2}{c}{ Very good } & \multicolumn{1}{c}{ Good } & \multicolumn{1}{c}{ Regular } & \multicolumn{1}{c}{ Bad } & Total \\
\hline & $\mathrm{n}$ & $\%$ & $\mathrm{n}$ & $\%$ & $\mathrm{n}$ & $\%$ & $\mathrm{n}$ & $\%$ & $\mathrm{n}$ & $\%$ & $\mathrm{n}$ \\
\hline Lower Lower (LL) & 6 & 3.5 & 5 & 2.9 & 16 & 9.3 & 9 & 5.2 & 1 & 0.6 & 37 & 21.5 \\
Upper Lower (UL) & 16 & 9.3 & 23 & 13.4 & 48 & 27.9 & 14 & 8.1 & 2 & 1.2 & 103 & 59.9 \\
Lower Middle (LM) & 4 & 2.3 & 4 & 2.3 & 10 & 5.8 & 6 & 3.5 & 1 & 0.6 & 25 & 14.5 \\
Middle (MI) & 1 & 0.6 & 1 & 0.6 & 1 & 0.6 & 3 & 1.7 & 1 & 0.6 & 7 & 4.1 \\
Total & 27 & 15.7 & 33 & 19.2 & 75 & 43.6 & 32 & 18.6 & 5 & 2.9 & 172 & 100 \\
\hline
\end{tabular}

Table 2 - Number and percentage of parents or guardians according to the perception of the general well-being due to their children's oral health and socioeconomic classes, Américo de Campos/Pontes Gestal, Brazil, 2015.

\begin{tabular}{lcccccccccccc}
\hline \multicolumn{8}{c}{ How much is your child's general well-being affected by the condition of his/her teeth, lips, jaws or mouth? } \\
\hline & \multicolumn{2}{c}{ Not at all } & \multicolumn{2}{c}{ Just a little } & More or less & A lot & \multicolumn{2}{c}{ Very much } \\
\hline & $\mathrm{n}$ & $\%$ & $\mathrm{n}$ & $\%$ & $\mathrm{n}$ & $\%$ & $\mathrm{n}$ & $\%$ & $\mathrm{n}$ & $\%$ & $\mathrm{n}$ & $\%$ \\
\hline Lower Lower (LL) & 20 & 11.6 & 7 & 4.1 & 8 & 4.6 & 2 & 1.2 & 0 & 0 & 37 & 21.5 \\
Upper Lower (UL) & 59 & 34.3 & 23 & 13.4 & 15 & 8.7 & 5 & 2.9 & 1 & 0.6 & 103 & 59.9 \\
Lower Middle (LM) & 8 & 4.6 & 3 & 1.7 & 6 & 3.5 & 8 & 4.7 & 0 & 0 & 25 & 14.5 \\
Middle (MI) & 2 & 1.2 & 1 & 0.6 & 2 & 1.2 & 2 & 1.1 & 0 & 0 & 7 & 4.1 \\
Total & 89 & 51.7 & 34 & 19.8 & 31 & 18 & 17 & 9.9 & 1 & 0.6 & 172 & 100 \\
\hline
\end{tabular}

Specifically in relation to the children feeling any pain, $62.8 \%$ of parents or guardians said that the children have had this experience.

Kruskal-Wallis test result was highly significant in all subscales of PCP-Q, with $\mathrm{p}<0.0001$, reason for which the analysis was furthered with Dunn's multiple comparison test. Concerning subscales "oral symptoms", "functional limitations", "social well-being" and "emotional well-being", Dunn test showed mean scores among social classes LL x LM, LL x MI, UL $x$ LM and UL $x$ MI with $p$ values less than the alpha level of 0.05 , being thus considered very significant. The subscale "oral symptoms" showed the greatest impact on the quality of life of all socioeconomic classes (Figure 1).

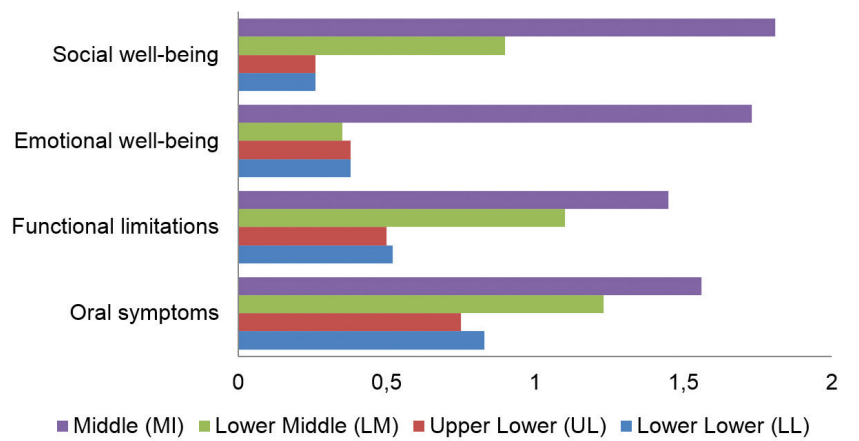

Fig.1. Relationship between the subscales of P-CPQ Index and socioeconomic classes, Américo de Campos/Pontes Gestal, Brazil, 2015.

\section{Discussion}

Quality of life encompasses meanings that reflect the individual's knowledge, experiences, expectations and values and is related to the factors that lead to health. Its main focus is the capacity to live disease-free or to overcome morbidity, pain and discomfort ${ }^{12}$. In this context, a close relationship is observed among social level, oral health and quality of life $\mathrm{e}^{13,14}$.

Parents are greatly responsible for their children's health. Therefore, it is of utmost importance to assess their perceptions of the oral health related to children and teenagers' well being and quality of life ${ }^{2}$.

Oral diseases present negative impact on the quality of life of children and teenagers because they lead to mastication difficulties, appetite decrease, weight loss, sleeping problems, behavioral changes, low self-esteem and decrease in academic performance ${ }^{1}$.

Even knowing all the consequences and damages that unsatisfactory oral health can bring, most parents in this study believed that the general well being of their children was little affected by their oral health, corroborating the finding of a study conducted with parents of children with brain disturbances, in which most participants reported that the general well-being of the children was "not at all" affected by their oral health. However, the responses might have been influenced by the specific conditions of those individuals for whom the oral health was not considered a priority ${ }^{15}$.

On the other hand, in a qualitative study the parents reported their great concern about their children's oral health, due to the possible negative interference in their future ${ }^{16}$. In another study, 
in which a questionnaire about quality of life and oral health was answered before and after the individuals had been submitted to dental treatment, the responses changed after the end of the treatment. This result shows that most participants considered that the general well-being is very much affected by the oral health, which influences both general health and social life ${ }^{17}$.

Oral disturbances have little impact on the quality of life of children and teenagers whose families belong to the upper socioeconomic classes. Nevertheless, they present a strong impact on the low income individuals, showing a significant relationship between lower social classes and the impact of oral diseases on the quality of life $\mathrm{e}^{18}$

This study presented statistically significant differences between socioeconomic classes and the parents' perception of the impact of oral diseases on the quality of life of their children. In all socioeconomic classes, the oral symptoms subscale showed the greatest impact.

Toothache caused by dental cavities and periodontal diseases are the main responsible for the impact of oral health on the individual's quality of life. This is highly present in the Brazilian population because the lower classes do not see oral health as a priority, as they have other urgencies, such food issues ${ }^{19-22}$. A study with individuals in an area encompassed by the Family Health Strategy Program showed that the participants who had seen a dentist three or more years ago, the ones with total prostheses and those with unsatisfactory oral hygiene belonged to the lower social classes and reported that they only sought dental care when they had a toothache, thus, not taking regular care of their dental health ${ }^{23}$.

Pain is the main reason parents seek dental care for their children ${ }^{13,22,24,25}$. In this study, pain was reported by a great portion of the participants, corroborating the finding of another study, in which the parents also reported the frequent occurrence of this symptom in their children ${ }^{22}$.

Public policies should be implemented to facilitate the access of the population to health care through preventive, educational and curative actions and activities. This will broaden the parents view about the importance of maintaining good oral health so that their children have quality of life.

New studies should be carried out with populations of higher social classes in order to confirm the relationship between socioeconomic level and parental perception of the impact of oral diseases on children's quality of life.

It may be concluded that there is an association between socioeconomic class and the individual's perception of parents or guardians about the impact of oral diseases on the quality of life of children.

\section{References}

1. Bica I, Duarte J, Camilo A, Jesus A, Ferreira, C; Oliveira F. [Oral healthrelated with quality of life: parental perceptions of childhood]. Millenium 2014 Jun-Dec;47:141-52. Portuguese.

2. Barbosa T, Mialhe FL, Castilho ARF, Gavião MBD. [Quality of life and oral health in children and adolescents: conceptual and methodological aspects]. Physis 2010;20(1):283-300. Portuguese.

3. Castilho AR, Mialhe FL, Barbosa TS, Puppin-Rontani RM. Influence of family environment on children's oral health: a systematic review. J Pediatr
(Rio J). 2013 Mar-Apr;89(2):116-23. doi: 10.1016/j.jped.2013.03.014.

4. Camargo MBJ, Barros AJD, Frazão P, Matijasevich A, Santos IS, Peres $M A$, et al. [Predictors of dental visits for routine check-ups and for the resolution of problems among preschool children]. Rev Saude Publica. 2012 Feb;46(1):87-97. Portuguese.

5. Paredes SO, Galvão RN, Fonseca FRA. [Influence of oral health on the life quality of preschool children]. Rev Baiana Saúde Pública 2014;38(1):12539. Portuguese.

6. World Health Organization, Division of Mental Health. Measurement of Quality of Life in Children. Geneva: World Health Organization; 1993.

7. Graciano MIG, Lehfeld NAS. [Socioeconomic study: indicators and methodology in a contemporary approach]. Rev Serv Soc Saúde. 2010;9(9):157-85. Portuguese.

8. Jokovic A, Locker D, Stephens M, Kenny D, Tompson B, Guyatt G. Measuring parental perceptions of child oral health-related quality of life. J Public Health Dent 2003 Apring;63(2):67-72.

9. Barbosa TD, Gavião MB. Validation of the Parental-Caregiver Perceptions Questionnaire: agreement between parental and child reports. J Public Health Dent. 2015 Fall;75(4):255-64. doi: 10.1111/j.17527325.2012.00371.x

10. Jokovic A, Locker D, Stephens M, Kenny D, Tompson B, Guyatt G. Validity and reliability of a questionnaire for measuring child oral-health-related quality of life. J Dent Res 2002 Jul;81(7):459-63.

11. Ayres M, Ayres Jr M, Ayres DL, Santos AS. [BioEstat 5.0: statistics applications in the areas of biomedical sciences [computer program]]. Belém: Ong Mamieraua; 2007. Portuguese.

12. Minayo MCS, Hartz ZMA, Buss PM. [Quality of life and health: a necessary debate]. Cienc Saude Colet. 2000;5(1):7-18. Portuguese.

13. Pandolfi M, Barcellos LA, Miotto MHMB, Goés PSA. [Oral health and dental services users' quality of life]. Pesq Bras Odontoped Clin Integr. 2011 Jul-Sep;11(3):311-6. Portuguese.

14. Vagetti GC, Moreira NB, Barbosa Filho VC, Oliveira V, Cancian CF, Mazzardo $O$, et al. [Aspects of quality of life associated with self-rated health: a study of elderly women from a physical activity program in lowincome neighborhoods in Curitiba in the state of Paraná, Brazil]. Cienc Saude Colet. 2013;18(12):3483-93. Portuguese.

15. Abanto J, Carvalho TS, Bonecker M, Ortega AOL, Ciamponi AL, Raggio DP. Parental reports of the oral health-related quality of life of children with cerebral palsy. BMC Oral Health 2012 Jun;12(15)1-8. doi: 10.1186/14726831-12-15

16. Abreu MHNG, Pordeus IA, Modena CM. [A social representation study of oral health among mothers in rural areas, Itaúna (MG), 2002]. Cienc Saude Colet. 2005;10(1):245-59. Portuguese.

17. Thomson WM, Foster Page LA, Gaynor WN, Malden PE. Short-form versions of the Parental-Caregivers Perceptions Questionnaire and the Family Impact Scale. Community Dent Oral Epidemiol 2013 Oct;41 (5):44150.

18. Locker D. Disparities in oral health-related quality of life in a population of Canadian children. Community Dent Oral Epidemiol 2007 Oct;35(5):34856.

19. Góes PSA. The prevalence and impact of dental pain in Brazilian schoolchildren and their families [thesis]. London: University College London; 2001.

20. Brazil. Ministry of Health of Brazil. [Department of Primary Care. Project SB Brazil 2010: national survey of oral health, the main results]. Brasilia: Ministry of Health; 2011 [cited 2015 Out 12]. Available in: http://dab. saude.gov.br/CNSB/sbbrasil/arquivos/projeto_sb2010_relatorio_final. pdf. Portuguese.

21. Costa SM, Vasconcelos M, Abreu MHNG. [Impact of dental caries on quality of life among adults resident in greater Belo Horizonte, State of Minas Gerais, Brazil]. Cienc Saude Colet. 2013;18(7):1971-80. Portuguese.

22. Silveira MF, Marôco JP, Freire RS, Martins AMEBL, Marcopito LF. [Impact 
of oral health on physical and psychosocial dimensions: an analysis using structural equation modeling]. Cad Saude Publica. 2014 Jun;30(6):116982. Portuguese.

23. Baldani MH, Brito WH, Lawder JAC, Mendes YBE, Silva FFM, Antunes JLF. [Individual determinants of dental care utilization among low-income adult and elderly individuals]. Rev Bras Epidemiol 2010;13(1):150-62.
Portuguese.

24. Edelstein BL. Disparities in oral health and access to care: findings of national surveys. Ambul Pediatr 2002;2(2):141-7.

25. Cohen-Carneiro F, Souza-Santos R, Rebelo MAB. Quality of life related to oral health: contribution from social factors. Cienc Saude Colet. 2011;16(Suppl 1):1007-15. 